\title{
Successful treatment of infantile oxysterol 7a-hydroxylase deficiency with oral chenodeoxycholic acid
}

\author{
Yun-Ping Tang ${ }^{1,2}$, Jing-Yu Gong ${ }^{1}$, Kenneth D. R. Setchell ${ }^{3}$, Wujuan Zhang ${ }^{3}$, Jing Zhao ${ }^{4}$ and Jian-She Wang ${ }^{4^{*}}$ (1)
}

\begin{abstract}
Background: Deficiency of oxysterol 7a-hydroxylase, encoded by CYP7B1, is associated with fatal infantile progressive intrahepatic cholestasis and hereditary spastic paraplegia type 5. Most reported patients with CYP7B1 mutations presenting with liver disease in infancy have died of liver failure. However, it was recently reported that two patients treated with chenodeoxycholic acid survived. Correlations between the phenotype and genotype of CYP7B1 deficiency have not been clearly established.

Case presentation: A 5-month-7-day-old Chinese baby from non-consanguineous parents was referred for progressive cholestasis and prolonged prothrombin time from one month of age. Genetic testing revealed compound heterozygous mutations c.187C > T(p.R63X)/c.334C > T(p.R112X) in CYP7B1, and fast atom bombardment mass spectrometry analysis of the urinary bile acid confirmed the presence of atypical hepatotoxic $3 \beta$-hydroxy- $\triangle^{5}$-bile acids. While awaiting liver transplantation she was orally administered chenodeoxycholic acid. Her liver function rapidly improved, urine atypical bile acids normalized, and she thrived well until the last follow-up at 23 months of age. Her 15-year-old brother, with no history of infantile cholestasis but harboring the same mutations in CYP7B1, had gait abnormality from 13 years of age. Neurological examination revealed hyper-reflexia and spasticity of the lower limbs. Brain MRI revealed enlarged perivascular space in the bilateral basal ganglia and white matter of frontal parietal.
\end{abstract}

Conclusions: In summary, these findings highlight that the phenotype of CYP7B1 deficiency varies widely, even in siblings and that early administration of chenodeoxycholic acid may improve prognosis.

Keywords: Cholestasis, Oxysterol 7a-hydroxylase, CYP7B1, Hereditary spastic paraplegia

\section{Background}

Congenital bile acid synthesis deficiencies (CBASD) are rare inherited metabolic diseases caused by a number of enzyme defects in the complex pathway of bile acid synthesis. Most are autosomal recessive genetic diseases, accounting for about $1-2 \%$ of the children with cholestatic disease [1]. Oxysterol $7 \alpha$-hydroxylase deficiency [2] caused by $C Y P 7 B 1$ mutations is also known as congenital

\footnotetext{
*Correspondence: jshwang@shmu.edu.cn

${ }^{4}$ The Center for Pediatric Liver Diseases, Children's Hospital of Fudan

University, 399 Wanyuan Road, Shanghai 201102, China

Full list of author information is available at the end of the article
}

bile acid synthesis defect type 3(CBASD3), and is characterized by neonatal cholestasis, and fat-soluble vitamin malabsorption. Most patients with CYP7B1 deficiency presenting with liver disease in infancy succumb to liver failure in early life. However, it was recently reported that two patients treated with chenodeoxycholic acid survived [3, 4]. In addition, hereditary spastic paraplegia type 5 (SPG5), which presents as neurological disease later in childhood or adulthood may also be associated with CYP7B1 mutations [5-10]. The CYP7B1 gene that encodes for the enzyme oxysterol 7a-hydroxylase is located on chromosome 8q21.3, and contains 6 exons and 5 introns, $202.6 \mathrm{~kb}$ in length. Correlations between 
the phenotype and genotype of $C Y P 7 B 1$ deficiency have not been clearly established [11, 12]. Here we describe the clinical features, laboratory examinations and treatment responses of an infant presenting with neonatal cholestasis, and her older brother presenting as SPG5, that further provides insight into this rare congenital bile acid synthesis disorder.

\section{Case presentation}

The proband is the second child of a non-consanguineous couple of Chinese origin, born at 39 weeks of gestation by vaginal delivery, with a birth weight of $3.15 \mathrm{~kg}$ and without any perinatal problems. She developed jaundice from one month of age and received treatment with oral ursodeoxycholic acid (UDCA $5 \mathrm{mg} / \mathrm{kg} / \mathrm{d}$ ), ganciclovir for cytomegalovirus DNA $2.92 \times 10^{3}$ copies $/ \mathrm{ml}$, immunoglobulin, albumin and a medium chain triglycerideenriched formula in a local hospital, but her condition worsened and she rapidly progressed to liver failure, and had two episodes of pneumonia presenting with cough, wheezing and fever. Whole exome sequencing was performed locally, and two heterozygous mutations of c.187C $>\mathrm{T}(\mathrm{p} . \mathrm{R} 63 \mathrm{X}) / \mathrm{c} .334 \mathrm{C}>\mathrm{T}(\mathrm{p} . \mathrm{R} 112 \mathrm{X})$ in CYP7B1 (Fig. 1) were revealed. She was admitted to Jinshan Hospital of Fudan University at the age of 5-months and 7-days old for a possible diagnosis of CBASD3.

On admission, she showed normal growth with a weight of $8.0 \mathrm{~kg}$ (50th-75th percentiles) and height of $65 \mathrm{~cm}$ (50th-75th percentiles). She was alert but not active. Physical examinations showed jaundice, grunting and tachypnoea. There were no dysmorphic features or cardiac murmur, auscultation revealed diffuse wheezing and rales in the lungs. The liver was firm and palpable at $3 \mathrm{~cm}$ below the right costal margin and the spleen was palpable at $4 \mathrm{~cm}$ below the left costal margin. Neurological examination was normal.

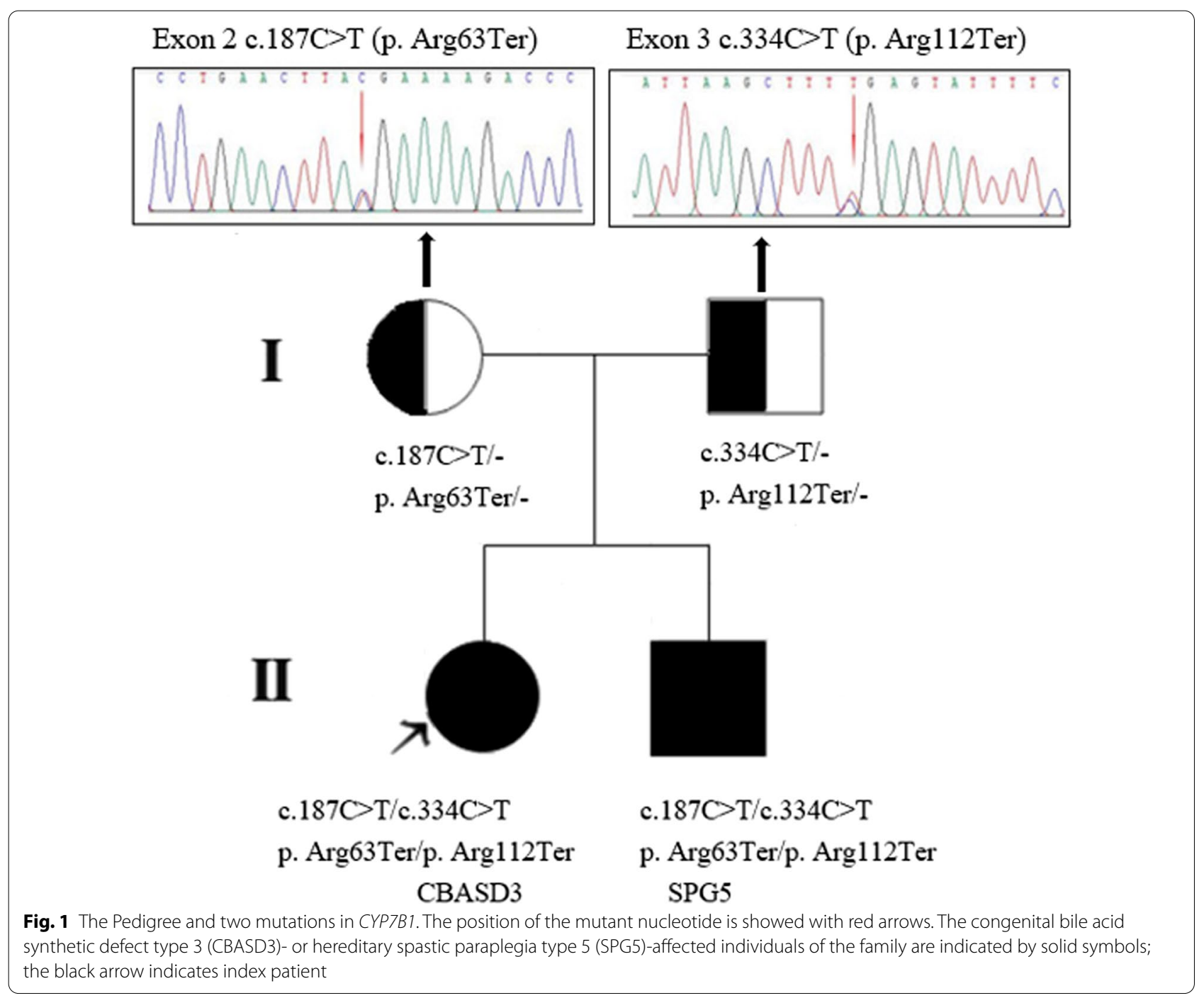


The laboratory investigations showed elevated levels of serum total bilirubin (TBIL), direct bilirubin (DBIL), alanine aminotransferase (ALT) and aspartate aminotransferase (AST), but normal $\gamma$-glutamyltransferase $(\gamma$-GT) (Table 1). The prothrombin time (PT) was prolonged and was only partly improved with parenteral vitamin K1 administration. Alpha-fetoprotein (AFP) was 241,863 ng/ $\mathrm{mL}$. The results of renal function, electrolyte levels and whole blood cell count and smear were all within normal ranges. The serological IgM of HAV, anti-HCV and HBsAg were all negative. The ultrasound of the abdomen showed hepatosplenomegaly and severe ascites.

She was intravenously administered albumin (7.5 g) for hypoproteinemia, and given oral supplementation of fat-soluble vitamins. Treatment of the pneumonia was with antibiotics and methylprednisolone $(2 \mathrm{mg} / \mathrm{kg} /$ day $)$. After a urine sample was collected for bile acid analysis (after 3 day's cessation of UDCA), oral chenodeoxycholic acid (CDCA, $6 \mathrm{mg} / \mathrm{kg} /$ day) was administrated from the age of 5-months-10-days. Two weeks later, her coagulation function improved, bilirubin level decreased, and the pneumonia resolved. After discharge from hospital, methylprednisolone was gradually reduced and discontinued but she was maintained on oral CDCA. Her liver function markers, including prothrombin time nearly normalized after 8 months of CDCA therapy and she thrived well until the last follow-up at 23 months of age (Table 1). Further urine samples were collected at 4 months and 8.5 months after the onset of CDCA therapy for bile acid analysis.

\section{Urine bile acid analysis by FAB-MS and LC-MS/MS}

The urinary bile acid profiling was analyzed at Cincinnati Children's Hospital Medical Center. Biochemical confirmation of a bile acid synthesis disorder was obtained following screening of urine using fast atom bombardment ionization-mass spectrometry (FAB-MS) [1, 2]. Confirmation of the identity of the major urinary atypical bile acids was performed by ultra-high performance liquid chromatography electrospray ionization-tandem mass spectrometry (LC-ESI-MS/MS) using a Waters TQ-XS triple quadruple mass spectrometer interfaced with an Equity HPLC system (Milford, MA). Nitrogen was the nebulizer gas and argon the collision gas. Negative ion collision-induced dissociation (CID) spectra were obtained by direct infusion of the urine extracts and with optimized collision energy. The urine extracts were further analyzed by LC-MS/MS with chromatography on a reverse phase column and with gradient elution, essentially as described previously [13]. The reference standard of the glyco-sulfate conjugate of $3 \beta$-hydroxy-5-cholenoic acid was used to permit identification confirmation based on the CID mass spectra and HPLC retention times, and a stable-labeled analog was used for quantification of urine concentrations. Bile acid concentration was also normalized to urinary creatinine concentration.

The profile of the first urine sample collected on admission revealed a marked elevation of bile acids consistent with significant cholestasis. The mass spectrum revealed elevated levels of glycine and sulfate conjugates of dihydroxy-, trihydroxy- and tetrahydroxy-cholanoic acids, residual to terminated UDCA therapy, and the presence of several atypical $3 \beta$-hydroxy- $\Delta^{5}$ bile acids (Fig. 2). The

Table 1 Evolution of liver and coagulation indices before and after CDCA

\begin{tabular}{|c|c|c|c|c|c|c|c|}
\hline & Pretreatment & $\begin{array}{l}\text { Starting CDCA } \\
\text { treatment }\end{array}$ & $\begin{array}{l}15 \text { days after } \\
\text { treatment }\end{array}$ & $\begin{array}{l}1 \text { months after } \\
\text { treatment }\end{array}$ & $\begin{array}{l}4 \text { months after } \\
\text { treatment }\end{array}$ & $\begin{array}{l}8 \text { months after } \\
\text { treatment }\end{array}$ & $\begin{array}{l}1 \text { year-8 months } \\
\text { after treatment }\end{array}$ \\
\hline $\operatorname{ALT}(7-40 U / L)$ & 133 & 127 & 127 & 104 & 74.9 & 47.4 & 24.6 \\
\hline AST (13-35U/L) & 206 & 129 & 115 & 122 & 64.2 & 47.7 & 35.5 \\
\hline TBIL (5-21 $\mu \mathrm{mol} / \mathrm{L})$ & 300 & 183 & 119.4 & 67.6 & 6 & 5.2 & 4.7 \\
\hline DBIL (0-3.4 $\mu \mathrm{mol} / \mathrm{L})$ & 150.4 & 78 & 54.5 & 29.2 & 2.9 & 2.1 & 1.6 \\
\hline TBA (0-10 $\mu \mathrm{mol} / \mathrm{L})$ & $100.9^{a}$ & $33.6^{b}$ & 54.5 & 65.2 & 12.8 & 4 & 4.9 \\
\hline ALP (35-135U/L) & 974 & 742 & 509 & 536 & 186 & 236 & 197 \\
\hline ү-GT (7-45U/L) & 27 & 26 & 94 & 183 & 132.7 & 34.1 & 18.4 \\
\hline ALB $(35-45 \mathrm{~g} / \mathrm{L})$ & 33 & 31 & 37 & 35 & 46.7 & 46.2 & 44.5 \\
\hline PT (9-12.5S) & 29 & 19.7 & 17.3 & 15.5 & 11 & 12.8 & 13.3 \\
\hline APTT (25.4-38.4S) & 75.1 & 47.8 & 46 & 37.9 & 41.7 & 35 & 34.2 \\
\hline INR (0.77-1.25) & 2.59 & 1.75 & 1.51 & 1.35 & 0.94 & 0.93 & 1 \\
\hline FIB (2.38-4.98 g/L) & 1.42 & 0.98 & 1.49 & 3.33 & 1.64 & 2.13 & 2.16 \\
\hline
\end{tabular}

ALT alkaline aminotransferase, $A S T$ aspartate aminotransferase, $T B I L$ total bilirubin, DBIL direct bilirubin, TBA total bile acids, $A L P$ alkaline phosphatase, $\gamma$-GT $\gamma$-glutamyltransferase, $A L B$ albumin, $P T$ prothrombin time, APTT activated partial thromboplastin time, INR international normalized ratio, FIB fibrinogen

a The value during the administration of UDCA

b TBA level significantly decreased after UDCA stopped 


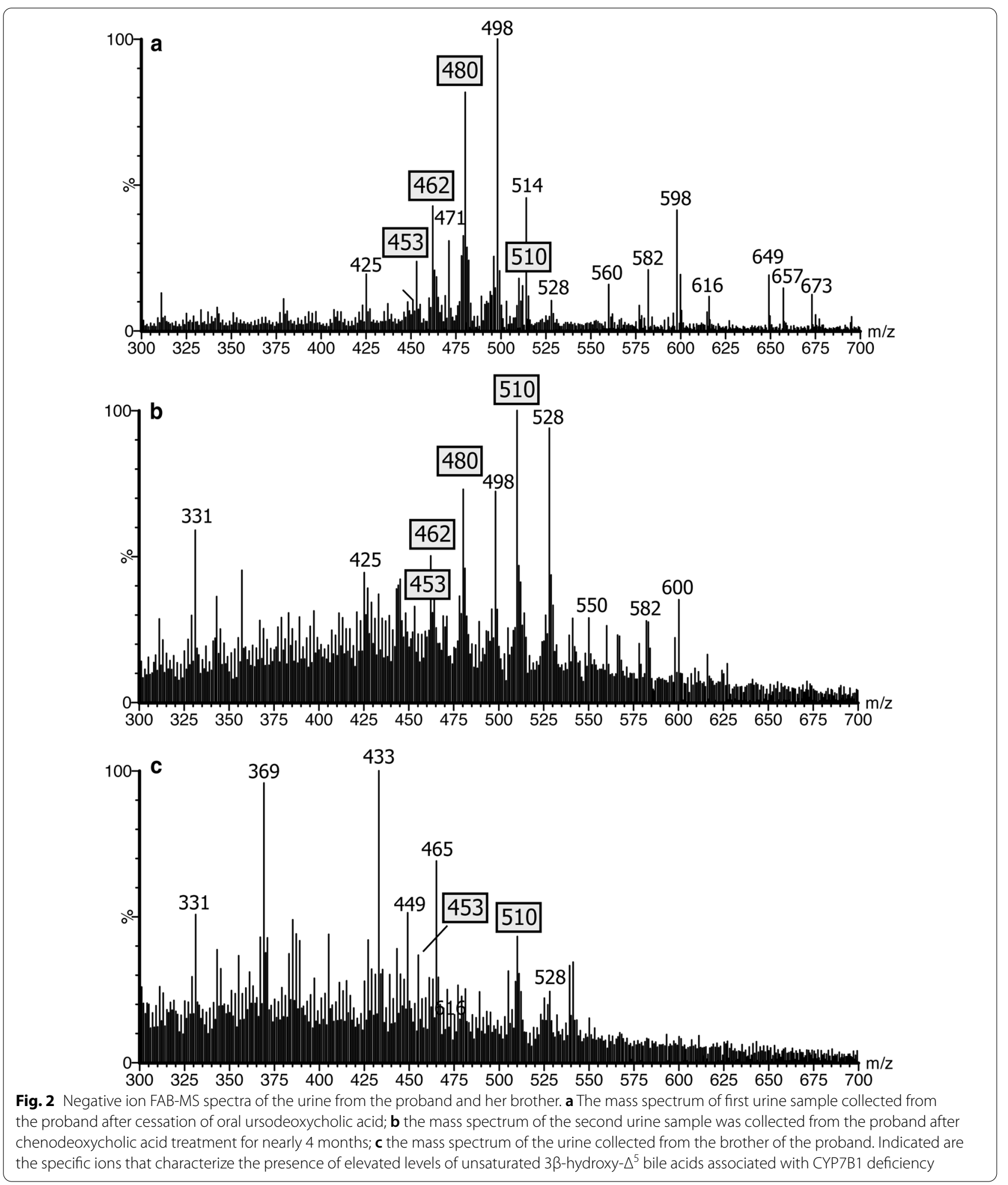

second urine sample collected 4 months after oral CDCA administration revealed high concentrations of atypical unsaturated monohydroxy bile acids as taurine, sulfate and glyco-sulfate conjugates. The ions at $\mathrm{m} / \mathrm{z}$ of 453,462 , 480 and 510 respectively are characteristic biomarkers for a CYP7B1 deficiency $[2,3]$ and these represent bile 
acid intermediates in the alternative 'acidic' pathway for bile acid synthesis (Fig. 2). The classical FAB-MS profile of urinary bile acids of patients with CYP7B1 deficiency [2] in the absence of any bile acid therapy, is characterized by the absence of the normal primary bile acid conjugates and the presence of increased concentrations of hepatotoxic $3 \beta$-hydroxy- $\Delta^{5}$ bile acids [2].

Definitive confirmation of the structures of the atypical urinary bile acids was further established by analysis of the urine extracts using direct-flow injection and LC-MS with electrospray ionization tandem mass spectrometry (ESI-MS/MS) and collision-induced dissociation (CID) of the parent ions of $\mathrm{m} / \mathrm{z} 510$ and $\mathrm{m} / \mathrm{z} 480$, the two most abundant ions in the FAB-MS spectrum (Fig. 3). The negative ion CID mass spectrum confirmed the parent $\mathrm{m} / \mathrm{z}$ 510 to be the glyco-sulfate conjugate of $3 \beta$-hydroxy-5cholenoic acid. The daughter ion at $\mathrm{m} / \mathrm{z} 97$ arises from the cleavage and loss of sulfate, and $\mathrm{m} / \mathrm{z} 74$ from cleavage of the glycine moiety on the side-chain. This CID mass spectrum thus eliminated the possibility that $\mathrm{m} / \mathrm{z} 510$ was from the taurine conjugate of 3-oxo- $7 \alpha, 12 \alpha$-dihydroxy4-cholenoic acid, which has the same nominal mass, and is a biomarker for the $\Delta^{4}$-3-oxosteroid $5 \beta$-reductase (AKR1D1) deficiency [14] and often elevated in early life, or with late-stage disease. Furthermore, the HPLC retention time of $\mathrm{m} / \mathrm{z} 510$ was identical to that of a pure reference compound of this bile acid (Fig. 3). Similarly, the ion at $\mathrm{m} / \mathrm{z} 480$ was shown from its negative ion CID mass spectrum to be consistent with the taurine conjugate of $3 \beta$-hydroxy-5-cholenoic acid, and not a glycine conjugated tetrahydroxy-cholanoic acid, which would have the same nominal mass. The daughter ions at $\mathrm{m} / \mathrm{z} 124,107$, 97 and 80 arise from cleavage of the taurine amino acid on the side-chain. The origins of these ions have been well characterized previously [15]. Although a reference compound of $\mathrm{m} / \mathrm{z} 480$ was unavailable, the LC-MS retention time and mass spectrum were found to be almost identical to that of tauro-lithocholic acid (these two bile acids would not be separated by HPLC under the conditions used) and the fragmentation pattern was similar, save an expected shift in mass of 2 Daltons for the parent ions (Fig. 3).

When the proband was referred to our hospital, the family history established that she had a 15-year-old brother attending junior middle school. Apart from obvious gait abnormality and poor school sports performance evident from 13 years of age, his past history was unremarkable. He developed gait paraparesis with slowly progressive aggravation, but without intellectual or psychological problems. Neurological examination revealed hyper-reflexia and spasticity of the lower limbs, which indicated the upper motor neuron damage. His liver function markers, serum lipids, coagulation function and whole blood cell counts were all found to be normal. Brain magnetic resonance imaging (MRI) showed hyperintensity in the bilateral basal ganglia and white matter of frontal parietal on T2-weighted imaging (T2WI) which was considered as the perivascular spaces enlarged (Fig. 4). According to the clinical manifestation, physical examinations and image results, diagnosis of the pure SPG5 was suspected. The CYP7B1 mutations identified in the proband were verified in him, and in the parents by Sanger sequencing. Compound heterozygous mutations were identified in him, and both parents were found to be heterozygous for each mutation, consistent with the autosomal recessive nature of bile acid synthesis disorders. He was then diagnosed as SPG5 and chose to be treated with CDCA $(6 \mathrm{mg} / \mathrm{kg} /$ day), the same treatment used for his sister, and began rehabilitation training at the specialized physiotherapy department. After commence of the treatment, his gait abnormality and poor school sports performance did not improve. He still tripped a lot, and one time he fell on the ground and needed aid from his schoolmates to stand up. In follow up, he was reported by the parents to be non-compliant to CDCA therapy and this treatment was terminated after 2 months.

FAB-MS analysis of his urine bile acid spectrum was unremarkable and essentially normal (Fig. 2c) reflecting absence of any cholestatic liver disease. Quantification of the urinary concentration of $3 \beta$-hydroxy-5-cholenoic acid glyco-sulfate, the major atypical urinary bile acid in CYP7B1 deficiency, confirmed marked elevations in concentration at baseline; $6.10 \mu \mathrm{mol} / \mathrm{L}$ for the proband and $8.8 \mu \mathrm{mol} / \mathrm{L}$ for the 15 -year-old brother (mean \pm SEM normal range for non-cholestatic patients $0.67 \pm 0.18 \mu \mathrm{mol} / \mathrm{L}$ and for cholestatic patients $1.18 \pm 0.36 \mu \mathrm{mol} / \mathrm{L}$, Setchell et al. unpublished in-house data). Oral administration of CDCA (6 mg/kg/day) led to a marked decrease in the urinary excretion of $3 \beta$-hydroxy-5-cholenoic acid glyco-sulfate in both patients, consistent with suppression in hepatic synthesis. Figure 5 depicts the changes in urinary excretion of this atypical bile acid when normalized to creatinine. In the proband, the concentration of this atypical bile acid normalized by 8.5 months. However, in the 15-year-old brother, after an initial response evidenced by a decrease in atypical bile acids, the levels of 3 $\beta$-hydroxy-5-cholenoic acid glyco-sulfate increased markedly when CDCA therapy ceased. These findings lend support for suppression of bile acid synthesis in the alternative (acidic) pathway by CDCA and a rebound when treatment is discontinued.

\section{Discussion and conclusions}

Bile acids are formed from cholesterol through a series of complex enzymatic reactions in the liver. A deficiency of oxysterol $7 \alpha$-hydrolase leads to the accumulation of 

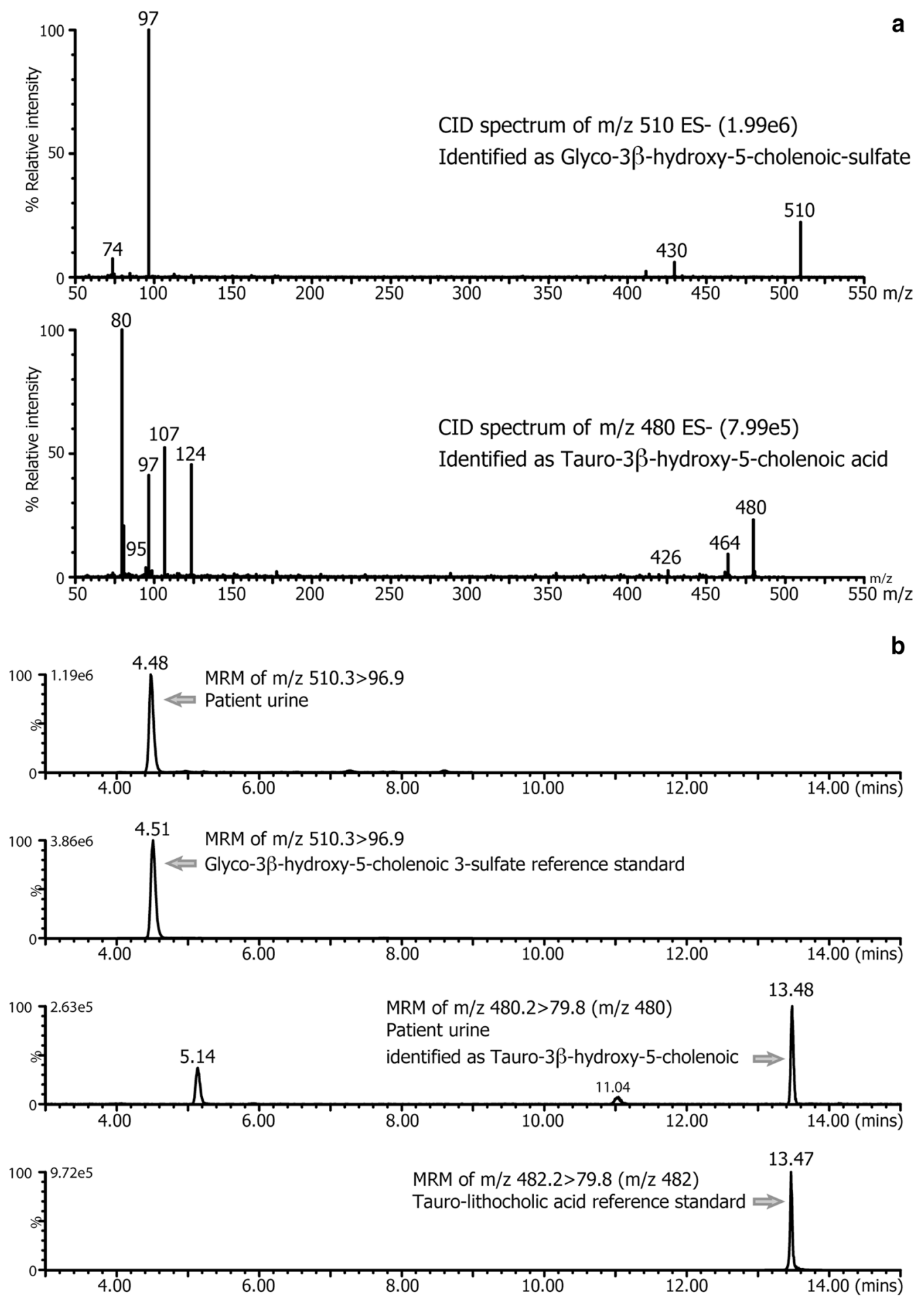

Fig. 3 Negative ion collision-induced dissociation mass spectra of a the parent ions m/z 510 and m/z 480 confirming these atypical bile acids as the glyco-sulfate and taurine conjugates, respectively, of $3 \beta$-hydroxy-5-cholenoic acids. $\mathbf{b}$ The LC-MS/MS mass chromatograms of the specific ion transitions for both compounds compared with a reference standard of the glyco-sulfate conjugate of 3 $\beta$-hydroxy-5-cholenoic acid and of tauro-lithocholic acid 


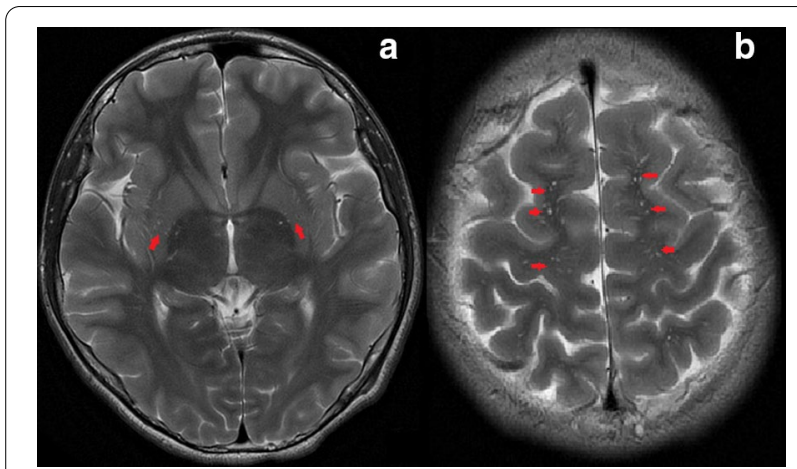

Fig. 4 Magnetic resonance imaging (MRI) data obtained from the brother with CYP7B1 deficiency, T2-weighted images show massively enlarged perivascular spaces (showed by red arrows) in the bilateral basal ganglia (a) and white matter of frontal parietal (b)
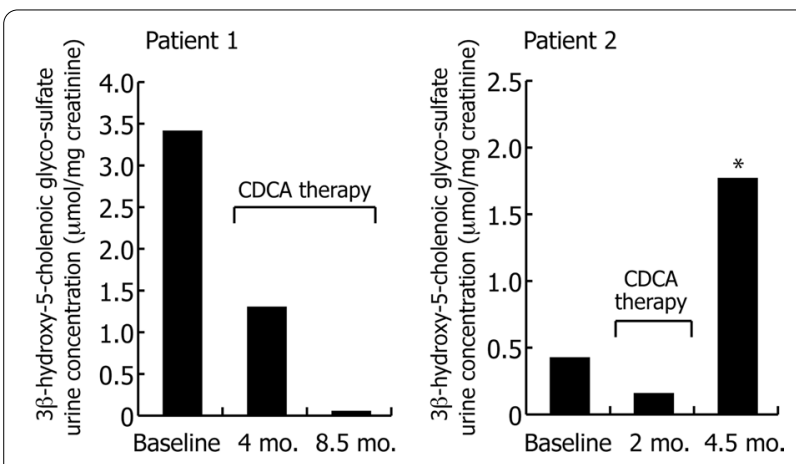

Fig. 5 Urine bile acid concentrations normalized to creatinine of the glyco-sulfate conjugate of $3 \beta$-hydroxy-5-cholenoic acid ( $\mathrm{m} / \mathrm{z} 510$ in the negative ion FAB-MS spectra) at baseline and after treatment with oral chenodeoxycholic acid in both patients with CYP7B1 deficiency. The asterix $\left(^{*}\right)$ denotes the patient was non-compliant and not taking chenodeoxycholic acid (CDCA) at the time of urine collection

hepatotoxic 3 3 -hydroxy-5-cholenoic acid and reduced levels of primary bile acids, the essential driving force for bile flow, which collectively leads to progressive cholestasis. Oxysterol $7 \alpha$-hydroxylase deficiency was first described in 1998 by Setchell et al. [2], presenting as neonatal cholestasis (CBASD3). Only 6 more cases have been reported thereafter (Table 2) [3, 4, 16-18]. With so few described patients, knowledge of the natural history of CSASD3 is limited. Consistent with the genetic analysis, the detection of increased concentrations of $3 \beta$-hydroxy- $\Delta^{5}$ bile acids in the urine confirmed CYP7B1 deficiency in the proband as another new case of CBASD3.

Table 2 summarizes the main features of all these published cases of CBASD3, together with the patient described here. In all, there were 5 males and 3 females, all presenting with prolonged jaundice and/or hepatosplenomegaly from between 6 days and 5 months after birth. All the infants were characterized by elevated conjugated bilirubin and transaminases, but normal $\gamma$-GT. All the patients had poor responses to UDCA therapy, including one patient that died of liver failure at the age of 11 months [16], and 2 patients that were liver transplanted at the age of 4 months [18], and 8 months [17] respectively. The others were treated with other medications after a diagnosis of CBASD3 was made. Based on these reports, UDCA clearly has no effect on the clinical course, partly because it does not inhibit bile acid synthesis and the production of atypical bile acids continues unabated.

Apart from our case, two other CBASD3 patients completely recovered after CDCA replacement therapy. One patient started CDCA $(15 \mathrm{mg} / \mathrm{kg} /$ day $)$ at the age of 4.5 months and liver function tests returned to normal by 7 months of age [3]; the other patient started CDCA $(15 \mathrm{mg} / \mathrm{kg} /$ day) at 3 months of age and the cholestasis resolved by age 5 months [4]. One treatment failure was reported in a patient that started CDCA $(9 \mathrm{mg} / \mathrm{kg} /$ day $)$ from 4 months of age, and then underwent liver transplantation at 1 year of age [4].

To date, only one patient has been treated with cholic acid (CA $15 \mathrm{mg} / \mathrm{kg} /$ day), for 49 days from 11 weeks of age, but then underwent cadaveric liver transplantation at the age of 4.5 months because of disease progression [2]. It is difficult to say with certainty that this primary bile acid is not helpful for patients with CBASD3.

Liver transplantation is believed the only choice for patients with CBASD3 who do not recover after drug treatment [16]. But the complications of the operation, infection, graft versus host disease, side-effects of longterm use of immunosuppressant impact prognosis. A total of four patients with CBASD3 have undergone liver transplantation $[2,4,17,18]$ and two died from complications; one from Epstein-Barr virus-related disseminated lymphproliferative disease on postoperative day 20 [2], the other from an intestinal perforation and sepsis on postoperative day 17 [4].

Why cholic acid failed, albeit in only one case, and chenodeoxycholic acid has proven helpful is difficult to explain. It may be that CDCA suppresses sterol 27-hydroxylase, the first step in the acidic pathway for bile acid synthesis, leading to decreased formation of atypical 3 3 -hydroxy-5-cholenoic acids, alleviating the liver damage and promoting bile flow. This would be supported by our evidence for reductions in the urinary concentrations of the major atypical bile acid in these patients, and the rebound in levels when there occurred non-compliance to therapy in the older child. 
Table 2 Clinical and laboratory features of the 8 patients with neonatal cholestasis caused by oxysterol 7a-hydroxylase (CYP7B1) deficiency

\begin{tabular}{|c|c|c|c|c|c|c|c|}
\hline Patient & Race & Sex & Age at first diagnosis & $\begin{array}{l}\text { Urine mass } \\
\text { spectrometry- } \\
\text { abnormal features }\end{array}$ & Organomegaly & CYP7B1 mutation & $\begin{array}{l}\text { Treatment and } \\
\text { outcome }\end{array}$ \\
\hline Setchell et al. [2] & Hispanic & M & 10 weeks & $\begin{array}{l}\text { Elevated } 3 \beta \text {-hydroxy- } \\
5 \text {-cholenoic acid }\end{array}$ & Hepatomegaly & R388X/R388X & $\begin{array}{l}\text { CA } 15 \mathrm{mg} / \mathrm{kg} / \mathrm{day} \text {, but } \\
\text { no response after } 49 \\
\text { d, CDLT at } 4.5 \mathrm{mo}, \\
\text { died at } 5 \mathrm{mo}\end{array}$ \\
\hline Ueki et al. [16] & Chinese & M & 5 months & $\begin{array}{l}\text { Elevated 3ß-hydroxy- } \\
\text { 5-cholen-24-oic } \\
\text { acid }\end{array}$ & Hepatosplenomegaly & R112X/R112X & UDCA, died at $11 \mathrm{mo}$ \\
\hline Mizuochi et al. [17] & Japanese & $\mathrm{F}$ & 6 months & $\begin{array}{l}\text { Elevated 33-hydroxy- } \\
\text { 5-cholen-24-oic } \\
\text { acid }\end{array}$ & Hepatosplenomegaly & R112X/R417C & $\begin{array}{l}\text { LDLT at } 8 \text { mo, alive } \\
\quad(29 \text { mo })\end{array}$ \\
\hline Dai et al. [3] & Pakistani & M & 3-4 months & 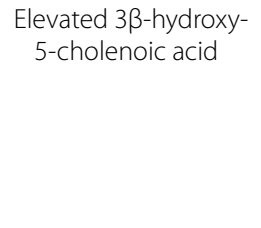 & normal & R417C/R417C & $\begin{array}{l}\text { CDCA } 15 \mathrm{mg} / \mathrm{kg} / \mathrm{day} \\
\text { firstly, improved } \\
\text { after } 2 \mathrm{~d} \text {, normal } \\
\text { liver function by } 7 \\
\text { mo, CDCA } 6 \mathrm{mg} / \mathrm{kg} / \\
\text { day at } 5 \text { years, alive } \\
\text { (6.5 years) }\end{array}$ \\
\hline Jeana et al. [18] & Korean & M & 3 months & $\begin{array}{l}\text { Elevated } 3 \beta \text {-hydroxy- } \\
\Delta^{5} \text {-bile acids }\end{array}$ & Hepatosplenomegaly & R338X/Y469lfs & $\begin{array}{l}\text { LDLT at } 4 \text { mo, alive } \\
\quad(33 \mathrm{mo})\end{array}$ \\
\hline Ju-Yin Chen et al. [4] & Chinese & M & 4 months & $\begin{array}{l}\text { Elevated } \\
3 \beta \text {-monohydroxy- } \\
\Delta^{5} \text {-bile acids }\end{array}$ & NR & R112X/R112X & $\begin{array}{l}\text { CDCA } 9 \text { mg/kg/day, } \\
\text { liver function dete- } \\
\text { riorated, LT at } 1 \text { year, } \\
\text { died at } 1 \text { year }\end{array}$ \\
\hline Ju-Yin Chen et al. [4] & Chinese & M & 3 months & $\begin{array}{l}\text { Elevated } \\
\text { 3ß-monohydroxy- } \\
\Delta^{5} \text {-bile acids }\end{array}$ & Hepatosplenomegaly & R112X/R112X & $\begin{array}{l}\text { CDCA } 15 \mathrm{mg} / \mathrm{kg} / \mathrm{day} \\
\text { firstly, liver function } \\
\text { improved after } 2 \mathrm{mo} \text {, } \\
\text { CDCA } 5 \mathrm{mg} / \mathrm{kg} / \text { day } \\
\text { at mo, alive (3 years) }\end{array}$ \\
\hline Present case & Chinese & $\mathrm{F}$ & 5 months & $\begin{array}{l}\text { Elevated } 3 \beta \text {-hydroxy- } \\
\Delta^{5} \text {-bile acids }\end{array}$ & Hepatosplenomegaly & $\mathrm{R} 63 \mathrm{X} / \mathrm{R} 112 \mathrm{X}$ & $\begin{array}{l}\text { CDCA } 6 \text { mg/kg/ } \\
\text { day, liver function } \\
\text { improved after } 7 \mathrm{~d} \text {, } \\
\text { alive (23 mo) }\end{array}$ \\
\hline
\end{tabular}

$M$ male, $F$ female, NR not reported, ND no data, UDCA ursodeoxycholic acid, CA cholic acid, CDCA chenodeoxycholic acid, CDLT cadaveric donor liver transplantation, LDLT living donor liver transplantation

The patient we described is the third case to date that has responded to treatment with CDCA.

Our observations also show that the phenotype of CYP7B1 deficiency is highly variable, even within siblings. In this report the sister had cholestasis early in life, while her brother with the same mutations in CYP7B1 developed the typical clinical features of SPG5, but without the liver disease. It therefore appears that there is no obvious correlation between the phenotype and genotype in CYP7B1 deficiency. Stiles et al. proposed the different manifestations of CYP7B1 defects may be caused by the accumulation of different $C Y P 7 B 1$ substrates in the body, leading to different clinical features [19]. However, a couple of siblings, who were diagnosed as SPG5 with compound heterozygous mutations (c.333_334delTC and c.806delA) as adults, were described as having a past history of prolonged neonatal jaundice [20]. So it is possible that a
CBASD3 infant that survives after CDCA therapy may suffer from SPG5 later.

There is no effective therapeutic strategy to improve the neurological disorder of patients with SPG5. In one report, CDCA treatment for SPG5 was reported to increase serum CDCA, lithocholic and UDCA, and decrease cholic acid and deoxycholic acid, but longterm studies are needed to draw conclusions as to its effectiveness [20]. The 15-year-old brother with SPG5 in this report was treated with CDCA for only 2 months. Although his second urinary bile acid profile was near normal, his neurological symptoms progressed, suggesting CDCA, at least in the short term, was not helpful.

Based on our observations of these two cases, we conclude that the bile acid profile of urine, and the clinical manifestations in cases of CYP7B1 deficiency vary widely, even within the same family. We believe that CDCA maybe the appropriate choice of therapy of this deficiency when 


\section{presenting as liver disease, and this may circumvent the need for liver transplantation.}

\begin{abstract}
Abbreviations
CBASD: Congenital bile acid synthesis deficiencies; CBASD3: Congenital bile acid synthesis defect type 3; CYP7B1: Oxysterol-7a-hydroxylase; SPG5: Hereditary spastic paraplegia type 5; UDCA: Ursodeoxycholic acid; TBIL:Total bilirubin; DBIL: Direct bilirubin; ALT: Alkaline aminotransferase; AST: Aspartate aminotransferase; $\gamma$-GT: $\gamma$-Glutamyltransferase; PT: Prothrombin time; AFP: Alpha-fetoprotein; CDCA: Chenodeoxycholic acid; FAB-MS: Fast atom bombardment mass spectrometry; LC-ESI-MS/MS: Liquid chromatography electrospray ionization-tandem mass spectrometry; CID: Collision-induced dissociation; MRI: Magnetic resonance imaging; T2Wl:T2-weighted imaging; TBA: Total bile acids; ALP: Alkaline phosphatase; ALB: Albumin; APTT: Activated partial thromboplastin time; INR: International normalized ratio; FIB: Fibrinogen; CA: Cholic acid.
\end{abstract}

\section{Acknowledgements}

Not applicable.

\section{Authors' contributions}

YPT and JYG contributed equally to this paper. WZ contributed the bile acid analysis. YPT, JYG, KDRS and JSW drafted the manuscript; JZ contributed the acquisition of clinical data. All authors read and approved the final manuscript.

\section{Funding}

Supported by the National Natural Science Foundation of China Nos. 81570468 and 81873543 (to JSW); HM Lui Fellowship Award Shanghai Training Program (to YPT). The funding bodies played no role in the design of the study and collection, analysis, and interpretation of data and in writing the manuscript.

\section{Availability of data and materials}

The datasets used and/or analyzed during the current study are available from the corresponding author on reasonable request.

\section{Declarations}

\section{Ethics approval and consent to participate}

This article is a retrospective study, so ethical approval was not necessary, and the Jinshan Hospital of Fudan University can offer an exempt ethical statement in support. The study conformed to the ethical guidelines of the Declaration of Helsinki 1975. Informed consent was obtained from the child's parents before the initiation of CDCA therapy.

\section{Consent for publication}

The patient's parents provided informed written consent for this publication.

\section{Competing interests}

Setchell KDR is a consultant to Retrophin San Diego, United States, and holds minor equity in Asklepion Pharmaceuticals; Wang JS consulted for Shanghai Ethypharm. The other authors declare no conflicts of interest.

\section{Author details}

${ }^{1}$ Department of Pediatrics, Jinshan Hospital, Fudan University, Shanghai 201508, China. ${ }^{2}$ Department of Gastroenterology, Qilu Children's Hospital of Shandong University, Jinan 250022, Shandong, China. ${ }^{3}$ Department of Pathology and Laboratory Medicine, Cincinnati Children's Hospital Medical Center, Cincinnati, OH 45229, USA. ${ }^{4}$ The Center for Pediatric Liver Diseases, Children's Hospital of Fudan University, 399 Wanyuan Road, Shanghai 201102, China.

Received: 9 November 2020 Accepted: 5 April 2021

Published online: 13 April 2021

\section{References}

1. Bove KE, Heubi JE, Balistreri WF, Setchell KDR. Bile acid synthetic defects and liver disease: a comprehensive review. Pediatr Dev Pathol. 2004;7(4):315-34. https://doi.org/10.1007/s10024-002-1201-8.

2. Setchell KDR, Schwarz M, O'Connell NC, Lund EG, Davis DL, Lathe R, et al. Identification of a new inborn error in bile acid synthesis: mutation of the oxysterol 7alpha-hydroxylase gene causes severe neonatal liver disease. J Clin Investig. 1998;102(9):1690-703. https://doi.org/10.1172/JCI2962.

3. Dai D, Mills PB, Footitt E, Gissen P, McClean P, Stahlschmidt J, et al. Liver disease in infancy caused by oxysterol 7a-hydroxylase deficiency: successful treatment with chenodeoxycholic acid. J Inherit Metab Dis. 2014;37(5):851-61. https://doi.org/10.1007/s10545-014-9695-6.

4. Chen JY, Wu JF, Kimura A, Nittono H, Liou BY, Lee CS, et al. AKR1D1 and CYP7B1 mutations in patients with inborn errors of bile acid metabolism: possibly underdiagnosed diseases. Pediatr Neonatol. 2019. https://doi. org/10.1016/j.pedneo.2019.06.009.

5. Hentati A, Pericak-Vance MA, Hung WY, Belal S, Laing N, Boustany RM, et al. Linkage of "pure" autosomal recessive familial spastic paraplegia to chromosome 8 markers and evidence of genetic locus heterogeneity. Hum Mol Genet. 1994;3(8):1263-7. https://doi.org/10.1093/hmg/3.8. 1263.

6. Klebe S, Durr A, Bouslam N, Grid D, Paternotte C, Depienne C, et al. Spastic paraplegia 5: locus refinement, candidate gene analysis and clinical description. Am J Med Genet B Neuropsychiatr Genet. 2007;144B(7):85461. https://doi.org/10.1002/ajmg.b.30518.

7. Tsaousidou Maria K, Ouahchi K, Warner Tom T, Yang Y, Simpson MA, Laing $N G$, et al. Sequence alterations within CYP7B1 implicate defective cholesterol homeostasis in motor-neuron degeneration. Am J Hum Genet. 2008;82(2):510-5. https://doi.org/10.1016/j.ajhg.2007.10.001.

8. Topaloğlu H, Pinarli G, Erdem H, Gücüyener K, Karaduman A, Topçu M, et al. Clinical observations in autosomal recessive spastic paraplegia in childhood and further evidence for genetic heterogeneity. Neuropediatrics. 1998;29(4):189-94. https://doi.org/10.1055/s-2007-973559.

9. Coutinho P, Barros J, Zemmouri R, Guimarães J, Alves C, Chorão R, et al. Clinical heterogeneity of autosomal recessive spastic paraplegias: analysis of 106 patients in 46 families. Arch Neurol. 1999;56(8):943-9. https://doi. org/10.1001/archneur.56.8.943.

10. Coutinho P, Ruano L, Loureiro JL, Cruz VT, Barros J, Tuna A, et al. Hereditary ataxia and spastic paraplegia in Portugal: a population-based prevalence study. JAMA Neurol. 2013;70(6):746-55. https://doi.org/10.1001/jaman eurol.2013.1707.

11. Mignarri A, Malandrini A, Del Puppo M, Magni A, Monti L, Ginanneschi F, et al. Treatment of SPG5 with cholesterol-lowering drugs. J Neurol. 2015;262(12):2783-5. https://doi.org/10.1007/s00415-015-7971-5.

12. Cecilia M, Foudil L, Dominique R, Alexandre L, Guillaume B, Lydie H, et al. Plasma oxysterols: biomarkers for diagnosis and treatment in spastic paraplegia type 5. Brain. 2018;141(1):72-84. https://doi.org/10.1093/ brain/awx297.

13. Zhang W, Jha P, Wolfe B, Gioiello A, Pellicciari R, Wang J, Heubi J, Setchell KDR. Tandem mass spectrometric determination of atypical $3 \beta$-hydroxy$\Delta 5$-bile acids in patients with $3 \beta$-hydroxy- $\Delta 5$-C27-steroid oxidoreductase deficiency: application to diagnosis and monitoring of bile acid therapeutic response. Clin Chem. 2015;61(7):955-63. https://doi.org/10.1373/ clinchem.2015.238238.

14. Setchell KDR, Suchy FJ, Welsh MB, Zimmer-Nechemias L, Heubi J, Balistreri WF. Delta 4-3-oxosteroid 5 beta-reductase deficiency described in identical twins with neonatal hepatitis. A new inborn error in bile acid synthesis. J Clin Investig. 1988;82:2148-57. https://doi.org/10.1172/JCI11 3837.

15. Sjövall J, Griffiths WJ, Setchell KDR, Mano N, Goto J. Analysis of bile acids. In: Makin HLJ, Gower DB, editors. Steroid analysis. New York: Springer; 2010. p. 837-966.

16. Ueki I, Kimura A, Nishiyori A, Chen HL, Takei H, Nittono H, Kurosawa T. Neonatal cholestatic liver disease in an Asian patient with a homozygous mutation in the oxysterol 7alpha-hydroxylase gene. J Pediatr Gastroenterol Nutr. 2008;46(4):465-9. https://doi.org/10.1097/MPG.0b013e3181 5 a9911.

17. Mizuochi T, Kimura A, Suzuki M, Ueki I, Takei H, Nittono H, et al. Successful heterozygous living donor liver transplantation for an oxysterol 7a-hydroxylase deficiency in a Japanese patient. Liver Transpl. 2011;17(9):1059-65. https://doi.org/10.1002/lt.22331. 
18. Hong J, Oh SH, Yoo HW, Nittono H, Kimura A, Kim KM. Complete recovery of oxysterol 7a-hydroxylase deficiency by living donor transplantation in a 4-month-old infant: the first Korean case report and literature review. J Korean Med Sci. 2018;33(51):e324. https://doi.org/10.3346/jkms.2018.33. e324.

19. Stiles AR, McDonald JG, Bauman DR, Russell DW. CYP7B1: one cytochrome P450, two human genetic diseases, and multiple physiological functions. J Biol Chem. 2009;284(42):28485-9. https://doi.org/10.1074/ jbc.R109.042168.
20. Mignarri A, Malandrini A, Del Puppo M, Magni A, Monti L, Ginanneschi F, et al. Hereditary spastic paraplegia type 5: a potentially treatable disorder of cholesterol metabolism. J Neurol. 2014;261(3):617-9. https://doi.org/ 10.1007/s00415-014-7253-7.

\section{Publisher's Note}

Springer Nature remains neutral with regard to jurisdictional claims in published maps and institutional affiliations.
Ready to submit your research? Choose BMC and benefit from:

- fast, convenient online submission

- thorough peer review by experienced researchers in your field

- rapid publication on acceptance

- support for research data, including large and complex data types

- gold Open Access which fosters wider collaboration and increased citations

- maximum visibility for your research: over $100 \mathrm{M}$ website views per year

At BMC, research is always in progress.

Learn more biomedcentral.com/submissions 